\title{
Structural Injustice and Socially Undocumented Oppression: Changing Tides in Refugee and Immigration Ethics
}

\author{
Lukas Schmid ${ }^{1}$ (D) \\ Accepted: 1 August 2021 / Published online: 18 August 2021 \\ (C) The Author(s) 2021
}

\begin{abstract}
In this review essay, I discuss two recent works in refugee and migration ethics, Serena Parekh's No Refuge: Ethics and the Global Refugee Crisis and Amy Reed-Sandoval's Socially Undocumented: Identity and Immigration Justice. I find that their methodological ambitions overlap significantly and that their arguments represent welcome and largely successful examinations of generally neglected issues. I also explain how both approaches could fruitfully learn from each other, and argue that they lay pioneering groundwork for future work to continue the analysis of only nascent modes and areas of inquiry.
\end{abstract}

Keywords Refugees $\cdot$ Immigration $\cdot$ Injustice $\cdot$ Oppression $\cdot$ Identity $\cdot$ States

Serena Parekh's (2020) No Refuge: Ethics and the Global Refugee Crisis and Amy ReedSandoval's (2020) Socially Undocumented: Identity and Immigration Justice, two recent books in refugee and migration ethics, successfully advance many hitherto neglected conversations and exemplify the field's recent methodological and substantive broadening, largely leaving behind ideal-world debates between statists and cosmopolitans, armchair philosophising about abstract obligations, and the dominant practice of theorising about refugees and migrants without giving their own professed experiences and concerns their proper due. In this review essay, beyond giving short overviews of both books' central claims and arguments, I take a deeper look at some of their common merits and shortcomings, highlighting especially both projects' admirable elevation of their subjects' voices and their promising applications of late philosopher Iris Marion Young's thought.

Parekh's No Refuge is divided in two parts. The first part introduces the unfamiliar reader to debates over how to define refugeehood (ch. 1), on the nature and justifications of moral

Lukas Schmid

Lukas.Schmid@eui.eu

1 Department of Political and Social Sciences, European University Institute, San Domenico di Fiesole, Fiesole, Italy 
obligations and their applications to 'our' relations with refugees (ch. 2), and whether states have specific moral obligations to accept refugees into their societies (ch. 3). Parekh's ambition here is to convince the layperson that, like it or not, 'we' do have some moral responsibilities towards refugees: we have obligations to protect refugees' human rights and dignity. But she also points out that while the literature broadly agrees that there are such obligations, it does not generally take these to create straightforward and uncontroversial practical guidance. States may have some obligations to take in refugees, but it is unclear how far these obligations extend, and if they always override conflicting values, such as political or cultural selfdetermination. But in this framing, what is at issue is merely to what extent states must come to the rescue of refugees. The second part of the book contests this framing. Rather than (only) one of rescue, Parekh argues, (especially Western) states play a central role in creating and shaping the miseries of refugees. Their actions, while perhaps individually permissible, converge to create conditions of structural injustice; conditions under which the promise of refuge remains out of reach for the great majority of those who desperately need it. According to Iris Young, on which Parekh draws for her analysis,

"[s]tructural injustice exists when the combined operation of actions in institutions puts large categories of people under a systematic threat of domination or deprivation of the means to develop and exercise their capacities [...]. Structural injustice occurs as a consequence of many individuals and institutions acting in pursuit of their particular goals and interests, within given institutional rules and accepted norms." (Young 2006: 114)

This model of injustice can account for unjust outcomes brought about by the interactions of generally legitimate state policies. States, so Parekh contends, have generally accepted rights to sovereign admission control, and so many of their immigration policies are not directly and intentionally unjust (cf. p 165-166). Nevertheless, the interlocking effects of these policies create unjust outcomes: the non-provision of basic dignity and human rights fulfilment to refugees. The structural injustice of the global refugee regime is that it fails to provide safe havens for the great many of those who need them most, thereby depriving them of the 'minimal conditions of dignity'. Instead, it permanently contains them in undignified refugee camps or lets them fend for themselves in urban slums (ch. 4) and makes it as hard as possible for them to reach Western states' shores, thereby forcing them into the unsafe and often extremely abusive hands of human smugglers (ch. 5). Rather than in terms of rescue, then, the current actions of (especially Western) states should predominantly be framed as contributing to and perpetuating the detrimental outcomes of structural injustice (ch. 6). While it is hard to morally blame states for often legitimate individual policies which create injustice only in conjunction with those of other states, this does not mean that we should not ascribe political responsibility for changing outcomes for the better. Indeed, as those who mainly generate and shape the rules regarding acceptable state behaviour towards refugees, Western states have a special political responsibility to create more just outcomes for refugees (p. 169-176).

Reed-Sandoval's Socially Undocumented shifts the focus from refugees to all those who face a common set of unjust immigration-related constraints, focusing especially on the U.S. context (cf. p. 37). Its overarching ambition is to pose and apply a new conceptual framework by which to understand the naked immigration-based relational inequality mostly (but not exclusively) exerted on racialized Latinx immigrants crossing the southern U.S. border (p. 810). Based on the relational egalitarianisms of Elizabeth Anderson and Iris Marion Young, the book's central motive is to conceptualize and defend the status of 'social undocumentedness' 
as a hitherto overlooked yet distinct and widely operative kind of oppressed social position. Persons are socially, rather than legally, undocumented when they "endure a common set of unjust, immigration-related constraints on the basis of being perceived to be undocumented" (p. 37; whole quotation italicized in original). Such constraints are unjust insofar as they are imposed "on the basis of morally arbitrary features such as race/ethnicity and class"; an imposition which functions to designate the socially undocumented as a group of social inferiors (p. 56). Reed-Sandoval draws on various theoretical resources, such as Linda Alcoff's account of social identity and Pierre Bourdieu's analysis of 'habitus', to argue that the specific oppression of social undocumentedness also shapes oppressed individuals' social identities, conditioning distinctive habitual behaviours and epistemic positions (chs. 2-3). Indeed, she takes these insights to be the central upshots of her ethnographic research on pregnant Mexican women who legally cross into the US to receive pre-natal care. These women's habits and experiences are conditioned by their specifically pernicious 'illegalization', as they in their socially undocumented pregnant state are perceived to be particularly suspicious aliens, unproductive and burdensome (ch. 4). But the resulting necessity to live in perpetual resistance against this racialized and classist oppression also generates resources to create strong community bonds and organize workplaces in Latinx immigrant communities, as Reed-Sandoval extrapolates from ethnographic evidence as well as pertinent cultural documents (ch. 5). Searching for solutions for socially undocumented oppression, Reed-Sandoval makes clear that traditional open-borders stances are not the answer. Indeed, widely endorsed 'emergency' qualifications to open borders, invokable to maintain basic social goods such as social welfare or cultural cohesion, would likely be misused to exacerbate the ideological perception of the socially undocumented as alien burdens to be shed from society (cf. p. 160-162; ch. 6). In any case, attempts at diminishing or abolishing socially undocumented oppression requires the articulation of feasible policy solutions under non-ideal circumstances (p. 166). We must begin such attempts by perceiving the harsh realities of the migrant journey into the U.S. itself as a fundamental injustice: the degrading circumstances of the journey reduces immigrants "to demeaning, immigration-related constraint in the mainstream U.S. imaginary - thus perpetuating a core aspect of socially undocumented oppression" (p. 180). These journeys act as 'theatres of inequality' which lead 'domestic' populations to stigmatize those who undertake them as inferior. To achieve relational egalitarian justice, it is therefore indispensable to demilitarize borders, both to diminish death and violence in migrant journeys and to dispel demeaning prejudices by disassociating "socially undocumented bodies from popular ideas about death in the desert, swimming across the Rio Bravo, running and hiding from immigration enforcement" (p. 185; cf. ch. 7). This ought to be coupled with domestic reforms, including the "expansion of Municipal ID programs" to get the socially-and-legally undocumented 'out of the shadows', the ceasing of 'image of inequality'-reinforcing deportations, and the revamping of US admission policy to end the exploitation of 'irregular' immigrant labour (p. 199-202).

While both books have several noteworthy qualities in common, I found their exemplary engagement with refugee and migrant voices particularly refreshing. Parekh's and ReedSandoval's accounts are deeply grounded in their subjects' experiences; one gets the persistent impression that the authors do not simply use migrants' testimonies to shore up their own existing preconceptions and theoretical aims, but as the proper and central objects of exposition, interpretation, and systematization. The resulting theories are commendable instances of testimonial justice which greatly enrich a subfield all too devoid of analytically sharp and normatively insightful ways of elevating the marginalized voices of those often at the centre of its interest. 
To the extent that both accounts are convincing (they largely are), then, one can easily read them as proving Sarah Fine's recent point that "[e]ngaging with refugees, other migrants, and displaced people, and trying to hear what they say about why they are or are not moving, what they need and desire, may provide an impeccable basis for trying to make universal prescriptions about [the global minimum which all are owed as a matter of justice]" (Fine 2019: 48). Consider first Parekh's No Refuge, concerned primarily with the fact that the inability to secure refuge puts out of reach the 'minimum conditions of human dignity' for the great many of the world's refugees. By structuring her explorations of how refuge has come to be out of reach around the testaments of many different refugees from different backgrounds and experiences, Parekh succeeds at unsettling simplistic pictures of what 'minimum dignity' entails for the requirements of basic justice whilst clarifying and illustrating how very real people contend with and navigate the global refuge regime's many binds and obstacles. All of this serves to refocus our attentions on what is at stake for those who must devote the work of their lives to securing basic dignity. For example, Parekh's serious examination of the testaments of refugees living in official refugee camps on the one hand, and in the shadows of urban centres on the other, allows her to extrapolate a simple yet remarkable insight with significant normative upshots: the striving for dignity is complex, and many prefer the autonomy and self-determination that comes with an economically and socially unsecured life in urban centres over the agency-depravation that comes with the secure provision of food and shelter in urban refugee camps (cf. ch. 4).

Similar things may be said about Socially Undocumented, which makes it clear from the outset that its aim is to provide "a 'bottom up' philosophical analysis through which [...] to engage the perspectives of socially undocumented people themselves as conveyed in the contexts of music, poetry, ethnographic interviews, and historical research" (p. 28-29). As a result, the first-hand experiences which form the backbone of the book's methodological structure, and especially Reed-Sandoval's ethnographic work with 'socially undocumented' pregnant women, are utilized as a foundation from which to wade into new conceptual territory. Without sustained engagement with the actual voices of the subjects which interest Reed-Sandoval, she would simply lack the means to diagnose a previously neglected yet ubiquitous kind of oppressive social relation. But once the accounts of the oppressed are taken seriously, common denominators emerge, theoretical concepts can be applied to systematize them, and neglected relations of injustice can be introduced into social consciousness. It is only through such engagement that we can begin to grasp how 'social' undocumentedness operates, harms, and structures social reality in ways that the concept of 'legal' undocumentedness cannot capture.

This emphasis on the importance of elevating the viewpoints of the deprived and oppressed - for the sake of testimonial justice as well as for the sake of creating more plausible theories is related to another aspect of the methodological shifts marshalled by both books, namely the renaissance of late theorist Iris Marion Young's particular brand of non-ideal theorising about egalitarian justice, applied to philosophical questions of migration and refugeehood (cf. also Owen 2019). Young famously insists, first, that theorizing about justice must begin with a thorough investigation of the concrete injustices people face in a non-ideal world; and, second, that such injustices are not always traceable to direct and clear moral wrongs by single actors but instead often the result of complex interactions of sometimes individually permissible actions, which makes unjust outcomes structural, and their wrongness impossible to capture with a lens atomically focused on individual behaviours. Engagement with these Youngian contributions is at the hearts of both books, with Reed-Sandoval's book focusing on an 
investigation of a concrete yet obscured injustice, and Parekh's account reframing the refugee ethics debate by exposing the structural injustice at work in the global refugee regime.

It is interesting to think about what both books' Youngian investigations could learn from each other. For instance, Parekh's account of structural injustice may be beneficially complemented with the development of a distinct conceptual toolbox for grasping the concrete oppression of being denied the 'minimal conditions of dignity' qua the inability of accessing refuge; an analysis like Parekh's would reverberate all the more if it provided us with a systematic account of the particular deprivation of the refugeless. To be sure, Parekh's elevation of refugee voices is suited to illuminate the picture, but it does not supply us with a sophisticated range of theoretical tools to conceptualize their own interpretations of their predicaments, their values, coping strategies, and modes of resistance. It is a testament to the strength of Youngian analysis that future work might want to complement the important insights of No Refuge by investigating more deeply if the refugeless face distinct kind(s) of oppression(s), and if so, what the distinguishing features of such oppression(s) should properly be taken to be. Are the experiences of the refugeless qua being refugeless similar enough constitute a shared social identity with a distinct 'interpretive horizon', epistemic standpoint, or practice of resistance? Where could an application of Young's 'five faces of oppression' analysis situate structural deprivation of refuge?

In Reed-Sandoval's investigation, would it be productive to grasp socially undocumented oppression as the outcome of structural injustice? Reed-Sandoval certainly seems to think so, taking up the term in her introductory discussion of relational egalitarianism, and declaring that "the focus here is not on determining exactly who ought to be held liable for unjust outcomes, but rather, on seeking to end oppressive relationships" (p. 23). But while the way in which social undocumentedness is oppressive seems to be graspable only within a framework that takes structures seriously, since the web of unjust obstacles it poses originates in the interacting perceptions and acts of many disperse actors, Reed-Sandoval does not deliver these insights through an explicit discussion of structural injustice. Open questions about social undocumentedness qua structural injustice thus remain aplenty and should stimulate future work. For instance, does the responsibility to end social undocumentedness not entail a requirement to eradicate structures of racism and classism at the heart of its construction, and how far may and must we go in the pursuit of such a sweeping enterprise? Can the structural injustice of socially undocumented oppression ultimately be solved in the institutional confines of fully sovereign exclusionary states, or does this model's inherent insideroutsider structure itself inevitably condition such inequitable outcomes?

Finally, and relatedly, if there is a flaw common to both books, it is their reluctance to investigate more deeply the role of the state and of dominant statist political forces in relation to the perpetuation of immigration-related injustice and oppression. Parekh's account acknowledges that states' detrimental treatment of refugees is not restricted to their complicity with structural injustice; their policies also sometimes inflict direct and intentional injustices on them (cf. p. 166-168). Nevertheless, this aspect of state behaviour is somewhat neglected in the ensuing analysis, which gives the wrong impression that directly and intentionally unjust deterrence measures are not ubiquitous. They are, and in a great many cases, refugee deaths and tragedies can be directly attributed to particular policies. Those who perpetrate these policies deserve moral blame and ought to face public resistance. It is important to stress the existence of structural injustice in the global refugee regime, but Parekh's analysis sometimes does this at the cost of glossing over the many direct acts of oppression orchestrated under seemingly legitimate state policies, such as immigration detention and the externalization of border enforcement to private actors and third states. Similarly, there is a worry 
that Reed-Sandoval's approach may neglect the question how dominant statist political actors are related to the perpetuation of violence and relational inequality against the socially undocumented. Indeed, her analysis of the importance of degrading journeys and 'theatres of inequality' for the creation of public perceptions which conspire to create oppressive obstacles provokes the further question if such perceptions are functional for the preservation of broader cultural, racial, economic, or political hegemonies, in which the U.S.'s ruling classes might well have vested interests. This is not to say that the perpetuation of such oppression is centrally and intentionally orchestrated and perpetrated rather than structural in character. But when the effects of structural injustice (in this case social undocumentedness) serve generally dominant social and political interests, erasing the injustice may become contingent on effective political contestation and ultimately radical political change rather than just targeted, 'surgical' policy interventions (a point also relevant to Parekh's ambition of countering the global refugee regime's structural injustice). Reed-Sandoval's analysis, then, opens the door towards theorizing about immigration-related oppression from a more critical perspective: it may be that the processes through which socially undocumented identity is created are important sites of ideological obfuscation, at which the creation and perpetuation of distorted narratives about migrants and migrations function to create divisions which serve to support hegemonic and perhaps more broadly unjust power relations. However, this possibility is not further investigated.

Notwithstanding these complaints, No Refuge and Socially Undocumented are remarkable works of scholarship which further the field in many ways, and which will influence the trajectories of the refugee and migration justice debate for years to come.

Funding Open access funding provided by European University Institute - Fiesole within the CRUI-CARE Agreement. I would like to thank Claudia Brunori and two anonymous referees for Ethical Theory and Moral Practice for valuable feedback.

Open Access This article is licensed under a Creative Commons Attribution 4.0 International License, which permits use, sharing, adaptation, distribution and reproduction in any medium or format, as long as you give appropriate credit to the original author(s) and the source, provide a link to the Creative Commons licence, and indicate if changes were made. The images or other third party material in this article are included in the article's Creative Commons licence, unless indicated otherwise in a credit line to the material. If material is not included in the article's Creative Commons licence and your intended use is not permitted by statutory regulation or exceeds the permitted use, you will need to obtain permission directly from the copyright holder. To view a copy of this licence, visit http://creativecommons.org/licenses/by/4.0/.

\section{References}

Fine S (2019) Refugees, safety, and a decent human life. Proc Aristot Soc 119(1):25-52

Owen D (2019) Migration, structural injustice and domination on 'race', mobility and transnational positional difference. J Ethn Migr Stud 46(12):2585-2601

Parekh S (2020) No refuge: ethics and the global refugee crisis. Oxford University Press, Oxford

Reed-Sandoval A (2020) Socially undocumented: identity and immigration justice. Oxford University Press, Oxford

Young IM (2006) Responsibility and global justice: a social connection model. Soc Philos Policy 23(1):102-130

Publisher's Note Springer Nature remains neutral with regard to jurisdictional claims in published maps and institutional affiliations. 